\title{
High-Temperature Superconducting dc Networks
}

\author{
B. K. Johnson, Member, IEEE, R. H. Lasseter, Fellow, IEEE, F. L. Alvarado, Fellow, IEEE, D. M. \\ Divan, Senior Member, IEEE, H. Singh, Student Member, IEEE, M. C. Chandorkar, Student Member, \\ IEEE, and R. Adapa, Senior Member, IEEE
}

\begin{abstract}
High-temperature superconducting de networks are studied as a feasible alternative to ac power transmission systems. The dc network operates at generation voltages allowing direct connection of the generators to the rectifiers, eliminating the need for high-voltage insulation and transformers. The dc system is based on a mesh-connected low-voltage high-current superconducting dc transmission network supplied by unit-connected generators. The dc system feeds many small inverters that pass controlled levels of real and reactive power to ac loads. This paper presents an overview of superconducting low-voltage dc transmission systems, starting with a discussion of the dc system. This discussion is followed by an overview of the operation of ac distribution systems connected to the superconducting dc mesh and then inverter topologies and control strategies required for interfacing the ac distribution systems to the dc mesh. The paper presents a conceptual overview of the operation of the system based on simulation studies.
\end{abstract}

\section{INTRODUCTION}

$\mathrm{T}$ HE discovery of high-temperature superconductivity [1] has sparked a great deal of interest in its application to the power area. One such application, low-voltage power transmission, is the subject of this paper. The complete superconducting power system would operate at optimum generator voltages, resulting in a single voltage level from generation to distribution subsystems. Lowvoltage operation eliminates the need for high-voltage insulation and large transformers, and removes the $I^{2} R$ losses from the transmission system.

Implementing an ac transmission system with high-temperature superconductors results in hysteretic losses in the superconductor and eddy current losses in the copper or aluminum matrix surrounding the superconducting material. Current levels may then be restricted to reduce losses, and the system voltage level will need to increase to transfer the same amount of power. Long ac transmission lines and cables require reactive compensation (shunt or series connected capacitors and inductors) to maintain

Manuscript received May 14, 1993; revised February 21, 1994. This work was supported by the National Science Foundation under grant 8818339 and by EPRI under project RP7911-12.

B. K. Johnson is with the Department of Electrical Engineering, University of Idaho, Moscow, ID 83844.

R. H. Lasseter, F. L. Alvarado, D. M. Divan, H. Singh, and M. C Chandorkar are with the Department of Electrical and Computer Engineering, University of Wisconsin, Madison, Madison, WI 53706.

R. Adapa is with EPRI, Palo Alto, CA 94303.

IEEE Log Number 9403162. power transfer capability and provide adequate voltage regulation [2]. Superconducting cables used for ac transmission would have similar compensation requirements.

A low-voltage dc (LVdc) superconducting transmission system eliminates the problem of ac losses, but introduces other system issues. A mesh-connected dc system improves reliability by providing redundant transmission paths. Difficulties with a superconducting mesh-connected LVdc system relate primarily to the distribution of steady-state and transient currents in the dc mesh [3], system protection, and power conversion issues. The $\mathrm{dc} / \mathrm{ac}$ conversion process injects harmonic currents onto the $\mathrm{dc}$ system that result in harmonic losses.

The dc system is controlled so the ac system sees the dc mesh as an asynchronous system capable of delivering power from generation sites to distribution substations without transmission losses. Control of the dc system takes advantage of superconducting cable properties. All nodes on the dc system reach the same steady-state voltages due to the lossless transmission lines [3]. The dc voltage level is maintained by voltage control at one or more of the rectifier terminals. Thus, voltage on the $\mathrm{dc}$ mesh is a system-wide quantity in the same fashion as frequency in conventional ac systems. Control can be based on a dc voltage droop scheme in the same manner as ac systems are controlled using frequency droop [4].

Interfacing the superconducting LVdc system with the ac system involves some interesting issues relating to the choice and control of converters. Direct connection of unit-connected generators to rectifier bridges allows new options in the design of both generators and rectifier bridges.

The study of superconducting LVdc power transmission systems can be broken down into three basic areas: 1) the dc mesh and unit-connected generators, 2) the ac load system, and 3) the $\mathrm{dc} / \mathrm{ac}$ inverter interface, with economic considerations seen as an all-encompassing issue. This paper begins with a discussion of the dc system and introduces a possible cable configuration. Key issues in the operation of the ac load systems are then discussed. This discussion is followed by an overview of the ac/dc interface to the load systems. Preliminary studies indicate that the operating costs of an LVdc transmission system are roughly competitive with those of normal system [5]. These studies did not consider capital costs, and are 
rather incomplete since there are still unknowns in the system design, so those results are not presented here.

\section{The Superconducting LVdc Mesh}

The basic power delivery system in the United States has remained unchanged for decades. The U.S. power system is dominated by a high-voltage ac transmission grid, with lower voltages for load centers and generation sites. The high-voltage levels in the transmission system are required to reduce resistive losses during power transmission. There has been limited penetration of dc transmission interspersed within the ac transmission system [6]. These dc systems are largely simple point-to-point systems with a single rectifier feeding a single inverter. Attempts have been made to build larger dc systems with more than two converters. These are multiterminal HVdc systems [6].

The ac losses present in superconductors suggest the possibility of using dc transmission. A superconducting transmission system could eventually replace an entire conventional transmission system, although this change would likely occur gradually. The dc transmission system must have a high degree of reliability. Therefore a multiterminal dc system is preferred to allow parallel transmission paths that are able to supply the load even with one of the lines removed, as is possible with conventional ac systems. The need for parallel transmission paths suggests a mesh-connected dc system, similar to the system shown in Fig. 1.

The use of superconductors with zero dc resistance would eliminate $I^{2} R$ losses in the transmission system, eliminating the need to operate the system at high voltages to reduce current levels. The system can instead be operated at optimum generation voltage levels, in the range of $10-15 \mathrm{kV}$, resulting in a low-voltage high-current transmission system. Operation in the $10-15 \mathrm{kV}(\mathrm{dc})$ range is also suitable for upper levels of the load distribution system.

A typical dc system would be fed by several generating stations, many of which could be unit connected. The unit-connected stations supply only the rectifier terminal, and do not need to maintain a fixed operating frequency to supply conventional ac loads. Therefore, the generator voltage magnitude and frequency are free to vary to maintain optimal energy production. The generator output voltage magnitude can be controlled to add a slow voltage control for the dc system (as is presently done to provide local voltage control on ac systems).

Operation of the dc system near the generator voltage levels would also eliminate the need for a high-voltage transformer connecting the generator to the rectifier. The generator could instead be connected directly to the rectifier. The generator output voltage waveforms could also be optimized for rectifier operation to increase conversion efficiency [7].

The dc system will supply a large number of inverter stations, possibly hundreds. Each inverter station would replace the transformer connecting the present subtrans-

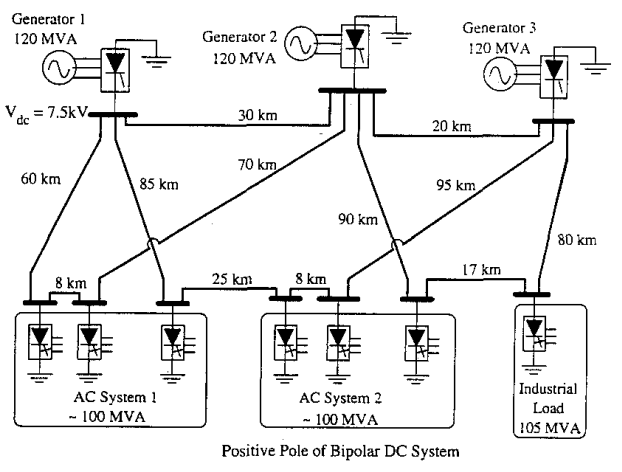

Fig. 1. Ten-terminal LVdc study system.

mission network ( $69 \mathrm{kV}-138 \mathrm{kV})$ to the distribution systems. The inverter stations would all use common design and construction, allowing them to be treated as "offthe-shelf" items. The inverter stations would utilize selfcommutating power semiconductor devices to allow them to control both voltage and frequency on the ac load system more rapidly and effectively than present ac systems.

\section{A. Sample System}

A ten-terminal sample system was developed to demonstrate the basic concepts for superconducting LVdc transmission systems. The layout for the sample system is shown in Fig. 1. The system consists of three rectifier terminals feeding a mesh that is loaded by seven inverter terminals. The dc system is bipolar (only one pole is shown in the figure), with voltage levels of $\pm 7.5 \mathrm{kV}$. Each of the generators is rated at $120 \mathrm{MVA}$, and supplies roughly $105 \mathrm{MW}$ (split between both poles). The rectifier stations consist of 3-5 modules connected in parallel, depending on the current ratings of the thyristors.

An LVdc transmission system is able to interface easily with energy storage elements since such schemes often use dc voltage or current. For example, a superconducting magnetic energy storage (SMES) coil or a battery storage facility can be connected to the dc system. Either of these would be interfaced through $\mathrm{dc}-\mathrm{dc}$ converters. The resulting converter interface will be much simpler to implement and control than an interface to an ac system since only one variable needs to be controlled (dc voltage or current) versus two for an ac interface (ac voltage magnitude and phase, for example).

\section{B. dc System Control}

Multiterminal HVdc (MTdc) systems use extensions of the system control techniques from two terminal systems. These techniques assume several control modes (loops) at each converter, with logic which decides between modes. Typical converter control modes found in two terminal systems include: dc voltage control, dc current control, constant inverter extinction angle, constant rectifier firing angle, and a voltage-dependent current limit. The transi- 
tion and set point of each control mode is tightly coordinated with the other converter and its control actions. Operational complexity becomes excessive as these concepts are extended to multiterminal systems, A five terminal system with two control modes per terminal has thirtytwo possible states of control. If the five-terminal system allows three control modes per terminal, there are over 200 operating states possible. If we add contingencies for loss of one terminal, additional complexity is added to the design of the controls.

It is difficult to build multiterminal systems with more than three or four terminals. The most complex systems in operation today use only three terminals. This limitation is in conflict with the desire to have small "off-the-shelf" converters which can be added to a system as load growth requires. This could involve hundreds of small converters at greatly reduced cost per $\mathrm{kW}$. To design such systems, the tight coordination between controls on different converters must be broken without reliance on fast communications.

Instead of using methods developed for point-to-point HVdc control, the paradigms of the ac system are more useful. Traditional ac systems have used to advantage the natural variability of demand with frequency and voltage. System frequency can be seen essentially as a constant in steady-state conditions, but frequency will decrease if load is increased, and increase if load decreases [8]. The supply system is designed, by means of the notion of frequency droop; to permit the balancing of demand with supply at all times, and to coordinate sharing of changes in power loading between all of the generators.

Each of the nodes on a superconducting dc system reaches the same steady-state voltage level since the superconductors do not present a dc resistance to cause terminal voltages to vary with line current magnitudes [3]. Thus, it is possible to use the voltage on the dc system as a signal, similar to the use of frequency in ac systems. The mesh dc voltage level can then be regulated through a joint-voltage regulation scheme. All of the rectifier terminals share voltage control through a voltage droop scheme [4]. This allows current to be shared among the converters to meet the system load, and avoids problems with overloading individual converters. The inverters vary local dc current in order to regulate real power supplied to the ac loads. A voltage droop scheme can be implemented for ordinary dc systems, but it is easier to implement for a superconducting system.

The analogy to generators is not perfect. The control of ac voltage provided by generators has no counterpart in the regulation of the dc mesh, since reactive power is not a valid concept for the dc network. Voltage replaces frequency as a system-wide signal, and there is no second quantity that needs regulation.

Each line commutated rectifier bridge has a current dependent voltage drop due to commutation overlap. This can be modeled as a resistance in steady-state converter models [6]. Rectifier operation in a constant firing angle mode can be modeled as a voltage source connected to the mesh through a resistance. Thus, line commutated rectifiers have a "built-in" droop. Changes in the current drawn off of the rectifiers alter the voltage drop across the resistance. The change in current divides between several rectifier terminals according to their equivalent resistances via current division. The system will settle into a new steady-state at a different voltage level following a change in total current. The slope of the droop characteristic can be varied by controlling the firing delay angle of the thyristors in the rectifier, [4]. The ability to control the sharing of incremental changes in system load between rectifiers is essential when individual converters approach their current limits.

This representation is sufficient for observing steadystate operating points. All of the nodes reach equal steady-state operating voltages. This is not adequate for representing the dynamics of the changes because the details of dc system are not included. The RL time constant between the slope of the droop characteristic, and the inductance in the path between a given rectifier and the inverter that changed its current demand, effects the response.

\section{A Possible Cable Design}

A bipolar dc system can be implemented using coaxial superconducting cables. The coaxial configuration results in the cancellation of radiated electromagnetic fields as well as providing a simple design for cooling purposes. The use of dc transmission also results in constant magnetic fields. Fig. 2 shows a possible cable configuration using liquid nitrogen as a coolant and a dielectric. This project assumed the use of thin film superconductors due to the greater current densities compared to bulk superconductors when the project began. The choice of cable configuration is not an essential part of the LVdc transmission system presented here.

\section{THE AC LOAD SYSTEMS}

The use of power electronics and alternative methods for controlling the transmission of power is increasing. Flexible ac transmission systems (FACTS) technologies are an example of this trend [9]. The superconducting LVdc technology proposed here is another, perhaps more radical example. A sample system was selected in order to conduct studies on a typical ac distribution system which may be supplied by such a system. A $13 \mathrm{kV}$ system based on one described in [10], was modified to represent an urban area. The system consists of 23 buses with 24 lines and cables, and forms three essentially radial networks as shown in Fig. 3. Each of these radial networks is connected to the superconducting dc mesh by an inverter terminal consisting of three or more modules rated at 10-15 MW (buses 660, 661, and 662). Each module will have sufficient overload capacity for the inverter to supply the rated load despite the loss of a single module. Transformers are available at two of the three substations ( 660 and 662), to consider the possibility of supply from a 


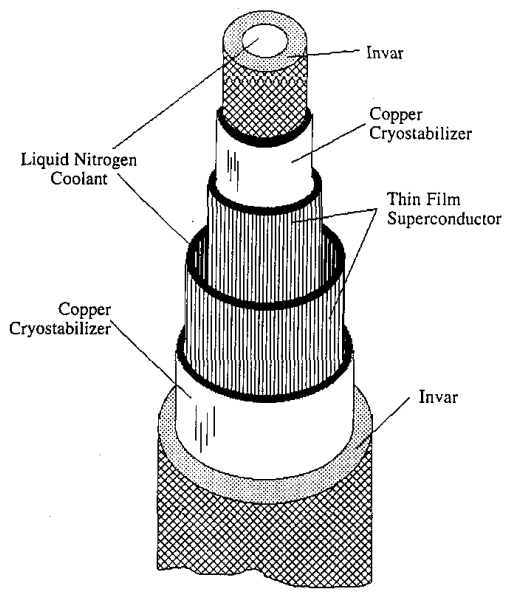

Fig. 2. Coaxial superconducting cable with liquid nitrogen coolant.

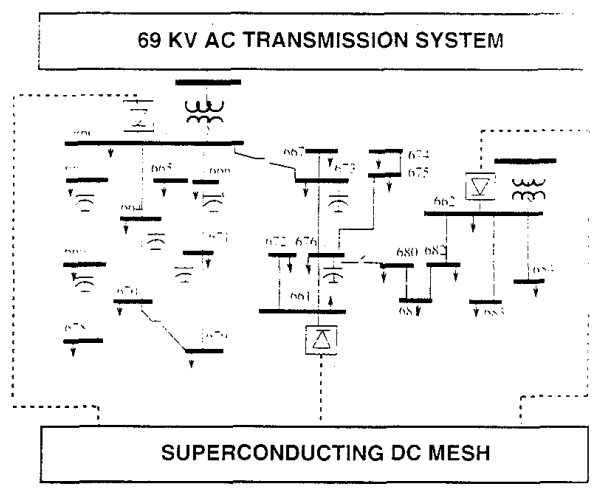

Fig. 3. ac system layout, including $69 \mathrm{kV}$ ac bus.

parallel $69 \mathrm{kV}$ ac system. This provides opportunity to model both active and passive ac systems.

\section{A. Operation Under ac Faults}

One of the most important distribution system design issues is designing a system capable of tolerating ac system faults. Supply of power by converters results in some important differences from conventional distribution systems. The converters behave as controlled ac current sources under fault conditions, so the usual voltage behind transient reactance model used for conventional systems is no longer appropriate. Current levels in the inverters are limited through control action to levels near the rated load currents due to power semiconductor current limits. Typical values range from $1.5 \mathrm{pu}$ to $2.0 \mathrm{pu}$ although currents of 3.0 pu may be permissible momentarily. Therefore, fault current levels are lower and make the task of detecting faults on the ac side more difficult. Possible remedies to the fault detection problem include (1) the use of fault current limiters (FCLs) in the inverter fed systems, (2) increasing the current limits on the inverter banks, and (3) the use of multiple smaller inverter banks with each bank supplying a single feeder. In such a configuration, a fault in one circuit would not cause voltage sags on any of the unfaulted circuits. Lower fault currents would force changes in present protection schemes, but they also provide advantages such as the reduction of current stresses on equipment.

\section{B. Interconnection of Radial Systems}

There may be occasions when it may be necessary to interconnect two or more of these radial subsystems, for example, if one of the inverters is inoperable. Then the load in one system must be fed by inverters in a neighboring subsystem. This scenario could result in inverters separated by some distance operating in parallel to supply a geographically distributed load. Frequency synchronization at the distribution level is assured by the HV system in present distribution systems, where overall system frequency is regulated by a "frequency droop" scheme at the generator stations. However, the proposed system requires that the "frequency droop" control be present at the inverter stations instead. This is complicated by potential dc-side interactions between inverter stations in addition to the ac-side interactions.

\section{Synchronization with ac Systems}

It is possible that a radial distribution feeder may already be connected to the $69 \mathrm{kV}$ ac subtransmission network in addition to the inverter interface with the dc mesh. Under such a scenario as in the case of the interconnection of two radial feeders connected to inverters, one has to deal with the issue of inverter voltage synchronization. The output voltage of the inverter (implemented using the time-integral of the voltage) must be matched both in magnitude and frequency to that of the ac system that it is to be connected to. Simulations performed using ACSL and EMTP to study the synchronization process indicate no difficulties with proper control settings. Some of the detailed results are presented in [11].

\section{THE DC / AC INVERTER INTERFACE}

The inverter interface between the dc mesh and the ac load system is a critical link to the success of the proposed system. Conventional HVdc transmission systems use thyristor-based line-commutated inverters [6]. These converters require an ac load system with a stiff voltage source, normally a large generator, to operate successfully. The line-commutated converter is only able to control the real power it supplies to the ac system, and cannot provide adequate control of the ac voltage magnitude (which will control reactive power). An ac system is considered "weak" if the converter supplies a high percentage of the power available to the load. An extreme case of a weak system is when there is no ac generation present at all other than the inverter. Such a system is referred to as a "passive" system.

The ac load distribution systems considered here may or may not have a direct connection to a larger ac transmission system. This means that the line voltage may not be available for commutation as is necessary in con- 
ventional thyristor-based converters used in HVdc applications. The inverter must therefore be capable of controlling both magnitude and the frequency of the power it supplies to the load system. Converters based on self-commutating switches are capable of meeting this requirement since they do not depend on the existence of an ac source [12]. A properly controlled self-commutated inverter can control both real and reactive power injections.

Self-commutated inverters based on the gate turn-off thyristor (GTO) [12] have been used in industry for uninterruptible power supply and variable speed drive applications, but have seen limited use at transmission power levels until recently due to device voltage and current limitations. However, the GTO voltage and current ratings have now increased to levels where they are suitable for LVdc systems. There are several existing GTO-based inverter topologies that meet the requirements of the LVdc system. The inverter topology chosen should be simple to reduce cost and increase reliability. The topology should permit proper control on the dc and ac side of the inverter interface. ac side control is primarily concerned with control of voltage magnitude and frequency. The selected topology needs to be evaluated in terms of the interactions with the systems on both the dc and ac sides. Each of the converter topologies will produce harmonics (voltages or currents at multiples of the fundamental ac frequency) on both the ac and dc sides of the inverter. Therefore, a topology and control scheme using simple filter configuration on the ac side is also desirable to reduce costs. Finally, the selected topology should behave in a satisfactory manner under abnormal operating conditions on the ac and dc sides. Based on these considerations, a number of topologies were considered which included the three-phase bridge voltage source inverter (VSI), the hybrid current source inverter (CSI) [13], and the neutral point clamped (NPC) inverter [14]. The VSI scheme was chosen for initial studies of the superconducting LVdc system. The basic configuration for a VSI is shown in Fig. 4. The basic circuit is fairly simple. The dc capacitor at the input of the inverter stores energy for transient changes in the load, and helps filter the dc voltage. The inductor on the ac side is the basic power transfer component between the inverter and the ac system. It also acts as a filter to reduce voltage harmonics.

The basic operating mode of the circuit is the six-step mode. In this mode, three switches conduct at any given instant. Each switch conducts for 180 degrees of the output voltage wave. With a constant dc bus voltage, as would exist on the superconducting dc mesh, it is not possible to control the amplitude of the fundamental component of the inverter output voltage. It's also not possible to control the harmonics. To control the fundamental component of the voltage, a "zero state" is used to introduce notches in the output voltage waveform. The addition of these notches is the basis of pulse width modulation (PWM), which can be used to control the magnitude of the ac voltage injection and also eliminate selected harmonics in some schemes. A higher switching

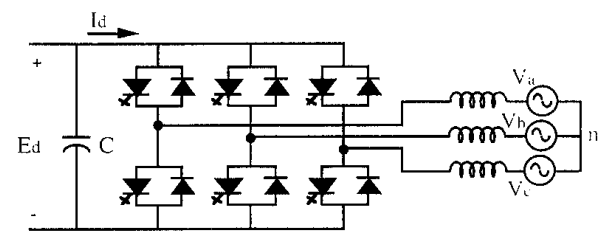

Fig. 4. Three-phase bridge VSI.

frequency leads to higher switching losses, while at the same time, the lower harmonics result in savings in the filter costs. Thus, a tradeoff is involved. Power losses pose a problem for implementing PWM converters for highpower applications. But the added benefits in lower filter costs, and more importantly, control over load voltage magnitude offset this problem in the superconducting LVdc system.

\section{NEAR-TERM APPLICATIONS}

The complete LVdc transmission system described here is a possible end result after decades of growth. Superconducting power transmission can be added gradually to work in concert with present ac transmission grids. A likely near-term application would be a high capacity infeed into an urban area. The infeed may initially be a point-to-point dc system. The infeed could follow an existing transmission corridor. However, the dc line could have much greater capacity than the conventional ac line it would replace.

The ability to add a high-capacity transmission line through an existing right of way is important since it is very difficult and costly to acquire new transmission corridors. Minimizing radiated magnetic fields may also be important when upgrading transmission lines in the future.

The system will be upgraded through the addition of parallel inverter taps along the line, and possibly additional rectifier taps. One drawback of dc transmission is the difficulty adding additional terminals to the system and then fitting these new terminals in the overall control scheme. The control scheme introduced in this paper does not suffer from control problems with these parallel taps as present systems do. Other lines would be added to the system, and eventually a multiterminal dc system would be constructed. The LVdc system would eventually replace conventional ac transmission following existing corridors. This concept may fit in well with the potential division of existing power utilities into generation, transmission, and distribution corporations. The ability to provide highcapacity low-cost transmission will be important for the transmission companies.

\section{CONCLUSION}

This paper has introduced a conceptual superconducting LVdc transmission system. The LVdc transmission system utilizes direct current transmission to avoid losses resulting from time-changing fluxes and currents in the superconducting material. The low-transmission voltage 
reduces the number of transformer stages necessary as well as reducing the need for high-voltage insulation. The low-voltage level allows for the direct connection of generators to the rectifier bridges, and also suggests the possibility of optimizing the generators to rectifier operation. The dc system could have tens of rectifier bridges feeding possibly hundreds of inverter terminals. The lowvoltage level allows for the use of self-commutated inverters that are capable of feeding very weak, or even passive ac systems. The discussion in this paper serves to provide an overview of a possible implementation of superconducting power transmission. A more detailed coverage of superconducting $\mathrm{LVdc}$ transmission systems can be found in [5].

\section{ACKNOWLEDGMENT}

This work forms a part of a project on High Temperature Superconducting dc networks. The authors would like to thank Eduardo Batalla for his contributions, especially in the cable design.

\section{REFERENCES}

[1] J. G. Bednorz and K. A. Muller, "Possible high $T_{c}$ superconductivity in the Ba-La-Cu-O system," Zeits. Physik, vol. B64, p. 189, 1986.

[2] T. J. Miller, Reactive Power Control in Electric Systems. New York: Wiley-Interscience, 1982.

[3] B. K. Johnson, R. H. Lasseter, and R. Adapa, "Power control applications on a superconducting LVdc mesh," IEEE Trans. Power Delivery, vol. 6, no. 3, pp. 1282-1288, 1991.

[4] B. K. Johnson, R. H. Lasseter, F. L. Alvarado, and R. Adapa, "Expandable multiterminal dc systems based on voltage droop," IEEE Trans. Power Del., vol. 8, no. 4, pp. 1926-1932, 1993.

[5] Superconducting LVDC Networks, EPRI TR-103636, Apr. 1994.

[6] J. Arrillaga, High-Voltage Direct Current Transmission. London, U.K.: Peregrinus, 1983.

[7] F. X. Wang and T. A. Lipo, "Analysis and steady-state behavior of an optimized ac converter machine," IEEE Trans. Power Apparat. Syst., vol. PAS-102, no. 8, pp. 2734-2742, Aug. 1983.

[8] N. Cohn, Control of Generation and Power Flow on Interconnected Poser Systems. New York: Wiley, 1961.

[9] G. B. Breuer, "Flexible ac transmission systems (FACTS): Scoping study." EPRI Rep. EL-6943, Sept. 1991.

[10] "Synthetic electric utility systems for evaluating advanced technologies," EPRI Rep. EM-285, Feb. 1977.

[11] M. C. Chandorkar, D. M. Divan, and R. Adapa, "Control of parallel connected inverters in stand-alone ac supply systems," IEEE Trans. Industry Appl., vol. 29, no. 1, pp. 136-143, Jan.-Feb. 1993.

[12] W. McMurray, "Feasibility of gate turnoff thyristors in a high-voltage direct current transmission system," EPRI Rep. EL-5332, Aug. 1987.

[13] S. G. Jalali and R. H. Lasseter, "Power conditioning systems for superconductive magnetic energy storage," IEEE Trans. Energy Conversion, vol. 6, no. 3, pp. 381-387, Sept. 1991.

[14] A. Nabae, I. Takahashi, and H. Akagi, "A new neutral point clamped inverter," IEEE Trans. Industry Appl., vol. IA-17, no. 5, pp. 518-523, Sept.-Oct. 1981.

Brian K. Johnson (S'86) received the Ph.D. degree in electrical engineering in 1992 from the University of Wisconsin, Madison, WI.

He is currently an Assistant Professor in the Department of Electrical Engineering at the University of Idaho, Moscow, ID. His interests include HVdc transmission, power systems, and power electronics. (Photograph not available at time of publication.)
Robert H. Lasseter (F'92) received the Ph.D. degree in physics at the University of Pennsylvania, Philadelphia, PA, in 1971.

He was a Consultant Engineer at General Electric Company until he joined the University of Wisconsin-Madison, WI, in 1980. His main interests are the application of power electronics to utility systems and simulation methods. (Photograph not available at time of publication.)

Fernando L. Alvarado (F'93) obtained the Ph.D. degree from the University of Michigan, Ann Arbor, MI.

He is currently a Professor at the University of Wisconsin in Madison in the Department of Electrical and Computer Engineering. His main interests are in computer applications to power systems and large scale problems. (Photograph not available at time of publication.)

Deepak M. Divan (M'83) received the M.Sc. and Ph.D. degrees in electrical engineering from the University of Calgary, Calgary, Canada, in 1979 and 1983, respectively.

$\mathrm{He}$ is presently an Associate Professor with the Department of Electrical and Computer Engineering at the University of Wisconsin, Madison. $\mathrm{He}$ is also Associate Director of the Wisconsin Electric Machines and Power Electronics Consortium (WEMPEC). His primary areas of interest are in power electronic converter circuits and control techniques. (Photograph not available at time of publication.)

Harmohan Singh (S'87) received the B.E.(Hons) degree from Panjab University, India in 1987 and the M.S. degree from The University of Alabama, in 1990, both in electrical engineering.

He is currently studying for the Ph.D. degree at the University of Wisconsin-Madison. His research interests include the application of optimization techniques in power systems. He has taught at The University of Alabama and at the University of Wisconsin-Madison, where he has been a Research Assistant since 1990. He worked with the Pacific Gas and Electric Company in the summer of 1992 and is a Member of SIAM and Eta Kappa Nu. (Photograph not available at time of publication.)

Mukul C. Chandorkar (S'90) received the B. Tech. degree in electrical engineering from the Indian Institute of Technology, Bombay, India, in 1984, and the M. Tech. degree in electrical engineering from the Indian Institute of Technology, Madras, India, in 1987.

He is currently a Ph.D. student in electrical and computer engineering at the University of Wisconsin-Madison, WI. (Photograph not available at time of publication.)
Rambabu Adapa received the Ph.D. degree in electrical engineering from the University of Waterloo, Ont., Canada, in 1986.

He joined the Power System Planning and Operation program of the Electric Power Research Institute (EPRI), Palo Alto, CA, in June 1989. Prior to joining EPRI, he was Staff Engineer in the Systems Engineering Department of McGraw Edison Power Systems, Franksville, WI. (Photograph not available at time of publication.) 